\title{
A obra de pesquisa de Ricardo Basbaum
}

\author{
The artwork of research of Ricardo Basbaum \\ La obra de investigación de Ricardo Basbaum
}

Vagner Godói

Universidade Estadual Paulista - Campus de Franca

E-mail: vagnergodoi@alumni.usp.br

ORCID: https://orcid.org/0000-0001-8739-5401

RESUMO:

O artigo discorre sobre o funcionamento de Você gostaria de participar de uma experiência artística?, de Ricardo Basbaum, com o objetivo de ressaltar a linha poética da pesquisa artística presente na obra deste artista. A obra de pesquisa é um processo de longa duração, tem um funcionamento que se desdobra no tempo, e resulta na criação de muitos conceitos de artista, que se espalham por um sistema complexo composto de várias partes, como objetos, diagramas, ideias, estruturas, conversas etc. Pode-se dizer que a obra de Ricardo Basbaum é uma obra de pesquisa, não só por estar relacionada com a universidade, mas também porque leva a pesquisa artística para variados circuitos artísticos.

Palavras-chave: Pesquisa artística. Teoria de artista. Discursividade. Transdisciplinaridade. Circuitos artísticos.

\section{ABSTRACT:}

This paper discusses the functioning of Ricardo Basbaum's Would you like to participate in an artistic experience?, with the aim of highlighting the poetic line of the artistic research present in the artist's work. The artwork of research is a long-term process, whose functioning develops with time and results in the creation of many artist concepts, which spread throughout a complex system composed of many parts, such as objects, diagrams, ideas, structures, conversations etc. It is possible to say that the work of Ricardo Basbaum is an artwork of research, not only because it is connected to academia but also because it takes artistic research to various art circuits.

Keywords: Artistic research. Artist theory. Discursivity. Transdisciplinarity. Artistic circuits.

GODÓI, Vagner. A obra de pesquisa de Ricardo Basbaum.

PÓS:Revista do Programa de Pós-graduação em Artes da EBA/UFMG. v. 11, n. 22, mai-ago. 2021

Disponível em < https://doi.org/10.35699/2237-5864.2021.25627> 


\section{RESUMEN:}

El presente artículo aborda el funcionamiento de ¿Le gustaría participar en una experiencia artística? de Ricardo Basbaum, con el objetivo de resaltar la línea poética de la investigación artística en la obra de este artista. La obra de investigación es un proceso de larga duración, tiene un funcionamiento que se prolonga en el tiempo, y su resultado es la creación de varios conceptos que se extienden por un sistema complejo compuesto por varias partes, como objetos, ideas, estructuras, charlas, etc. Se puede decir que la obra de Ricardo Basbaum es una obra de investigación, no solo por estar relacionada con la universidad, sino también porque lleva la investigación artística a variados circuitos artísticos.

Palabras clave: Investigación artística. Teoría de artista. Discursividad. Transdisciplinaridad. Circuitos artísticos.

Artigo recebido em: 01/10/2020

Artigo aprovado em: 06/04/2021 


\section{Materialidade da pesquisa artística}

Convergências e superposições entre texto e obra de arte, dissertação de mestrado de Ricardo Basbaum, hoje professor do Departamento de Arte da Universidade Federal Fluminense (UFF), está reproduzida na primeira parte ${ }^{1}$ do seu livro Além da pureza visual. Fundamentado pelas leituras de Michel Foucault (e sobre conceitos como enunciados, visibilidades e discurso) e também de Gilles Deleuze e/ou Félix Guattari (e sobre conceitos como conceito, regimes de signos, rizoma, máquina abstrata, diagrama etc.), o livro fala sobre as relações entre texto e obra de arte, sobre os diagramas e também sobre o texto como obra de arte (BASBAUM, 2007a). Assim, Basbaum aproxima-se: de artistas que trabalham a discursividade, a relação entre texto e imagem (ou diagrama), e o texto como obra de arte, tais como Marcel Duchamp, Joseph Kosuth, On Kawara, Paul Klee, René Magritte e o grupo Art \& Language; de experiências como o livro Aparelhos, colaboração entre o artista Waltercio Caldas e o crítico de arte Ronaldo Brito, uma "reflexão sobre a condição contemporânea da arte, envolvendo um pensamento sobre o funcionamento da obra, uma análise acerca do sistema de arte e seus limites"; de Lygia Clark, por conta da ideia de "linha orgânica"; e aproxima-se também de Hélio Oiticica, já que suas últimas obras têm um "sofisticado aparelho visual-conceitual" (BASBAUM, 2007, p. 102). Basbaum diz que todos os artistas que ele admira ou de quem procura se aproximar pensam na produção da obra de arte ao lado da produção discursiva.

"Teoria de artista", conceito elaborado na tese de doutorado de Ricardo Basbaum, defendida no Programa de Pós-graduação em Artes Visuais da Escola de Comunicações e Artes da Universidade de São Paulo (ECA-USP), é um procedimento de trabalho que coloca a teoria e a pesquisa como materiais, ferramentas, estratégias e métodos principais do artista contemporâneo, envolvendo tanto produção de textos como obras de arte, "articulando teoria e prática a partir de um sistema de revezamentos plástico-discursivos" (BASBAUM, 2008).

O artista recriou esse conceito a partir da apropriação da expressão contida no texto "Reflection on/as Artists' Theories", publicado em 2006, pelo artista-pesquisador alemão Michael Lingner, professor de História da Arte na Universidade de Ciências Aplicadas de Hamburgo. Segundo esse autor, desde o romantismo, a teoria de artista vem sendo uma condição implícita da prática artística, sendo um dos elementos fundamentais para a produção artística de vanguarda. As

GODÓI, Vagner. A obra de pesquisa de Ricardo Basbaum.

PÓS:Revista do Programa de Pós-graduação em Artes da EBA/UFMG. v. 11, n. 22, mai-ago. 2021 Disponível em < https://doi.org/10.35699/2237-5864.2021.25627> 
análises de Lingner se basearam nos escritos e nas teorias dos artistas Philipp Otto Runge, sobre a paisagem romântica; Adolf Hölzel, na passagem da Jugendstil para a arte abstrata; e Joseph Kosuth, na fronteira entre teoria e obra de arte. Fundamentado em Theodor Adorno, que alerta para a necessidade de consistência das teorias feitas pelos artistas, e Hans Belting, que fala sobre a necessidade de uma colaboração entre críticos, teóricos e artistas, o autor diz que a necessidade dos artistas em teorizar é um fator decisivo para a produção artística. As teorias de artistas podem ser produzidas dentro da universidade, e, mesmo que haja ambições científicas, o caráter subjetivo e, às vezes, confessional não deve ser desconsiderado fator que dispara embates e também reservas a respeito deste tipo de produção (LINGNER, 2006).

Ricardo Basbaum tem uma atividade intensa de criação de textos sobre a própria obra, criando um sistema conceitual que articula discursividade com a materialidade da produção artística. $\mathrm{O}$ artista nomeia seus escritos e suas teorias de artista por meio da ideia de ensaio-ficção. A expressão "ficção" entra para destacar a qualidade de "uma escrita que não abdica de um rigor qualquer, não abdica de uma produção conceitual, mas que quer se inscrever em um registro poético da reinvenção contínua".2 A expressão encontra-se no diagrama do projeto Você gostaria...?, e está próxima dos três conceitos chamados de tríade de NBP. A tríade de conceitos apareceu pela primeira vez no texto "O que é NBP?" e é composta das seguintes ideias: 1) imaterialidade do corpo; 2) materialidade do pensamento; e 3) logos instantâneo (BASBAUM, 1993). O artista desenvolve a ideia de materialidade do pensamento nestes termos:

O pensamento como algo que pode ser lançado, moldado, construído, acumulado, recolhido, contraído, expandido, amassado, jogado, corroído, revelado, ampliado, amplificado, estilhaçado, dissolvido, etc. O pensamento envolve as coisas, entre elas existe a atmosfera, com oxigênio, nitrogênio, gás carbônico, enxofre, chumbo, alumínio; mas também partículas de pensamento. Essas partículas desprendem-se dos nossos corpos e cérebros em fluxos além de nosso controle, aderindo aos objetos e a outros pensamentos; possuem campos gravitacionais e magnéticos potentes, e distorcem e alteram imagens, todas as imagens das coisas. O pensamento é, portanto, essencialmente carregado de potencialidade plástica (BASBAUM et al., 2014).

A teoria de artista funciona como um sistema de revezamentos plástico-discursivos, "admitindo a prática do artista funcionando nos termos de uma dupla-articulação visualidade/texto, acionando tanto a materialidade do conceito como a imaterialidade do visível" (BASBAUM, 2008, p. 45-46).

GODÓI, Vagner. A obra de pesquisa de Ricardo Basbaum.

PÓS:Revista do Programa de Pós-graduação em Artes da EBA/UFMG. v. 11, n. 22, mai-ago. 2021 Disponível em < $\underline{\text { https://doi.org/10.35699/2237-5864.2021.25627 }>~}$ 
Existe uma ligação entre a noção de ensaio-ficção proposta pelo artista e as ideias de materialidade, tanto do pensamento quanto da teoria, em que a linguagem é tratada como "matéria flexível, massa informe a ser plasmada a partir de múltiplos recursos" (BASBAUM, 2008, p. 101).

Ricardo Basbaum 3 diz que "ensaio-ficção" é um termo foucaultiano, porque "Foucault está em um embate com uma certa academia também, uma certa metodologia que impediria que ele colocasse o pensamento dele em um registro da urgência do presente". Aqui, o artista problematiza a questão dos protocolos da academia, que poderiam atrapalhar o desenvolvimento pleno e livre das ideias elaboradas em uma pesquisa artística, determinadas por protocolos que prejudicariam uma liberdade de trabalhar sobre a arte e as questões de agora. Por isso ele busca uma "escrita que fique, seja na academia, seja fora da academia, reivindicando um status do poético". E este escrito do artista também é a teoria que o artista faz sobre a sua própria obra. No caso de uma dissertação, tese ou qualquer outro tipo de resultado teórico proporcionado pela pesquisa artística, pode-se imaginá-la também como um ensaio-ficção, uma "escrita que envolve os rigores do ensaio e as aventuras da ficção".

GODÓI, Vagner. A obra de pesquisa de Ricardo Basbaum.

PÓS:Revista do Programa de Pós-graduação em Artes da EBA/UFMG. v. 11, n. 22, mai-ago. 2021 Disponível em < $\underline{\text { https://doi.org/10.35699/2237-5864.2021.25627 }>~}$ 


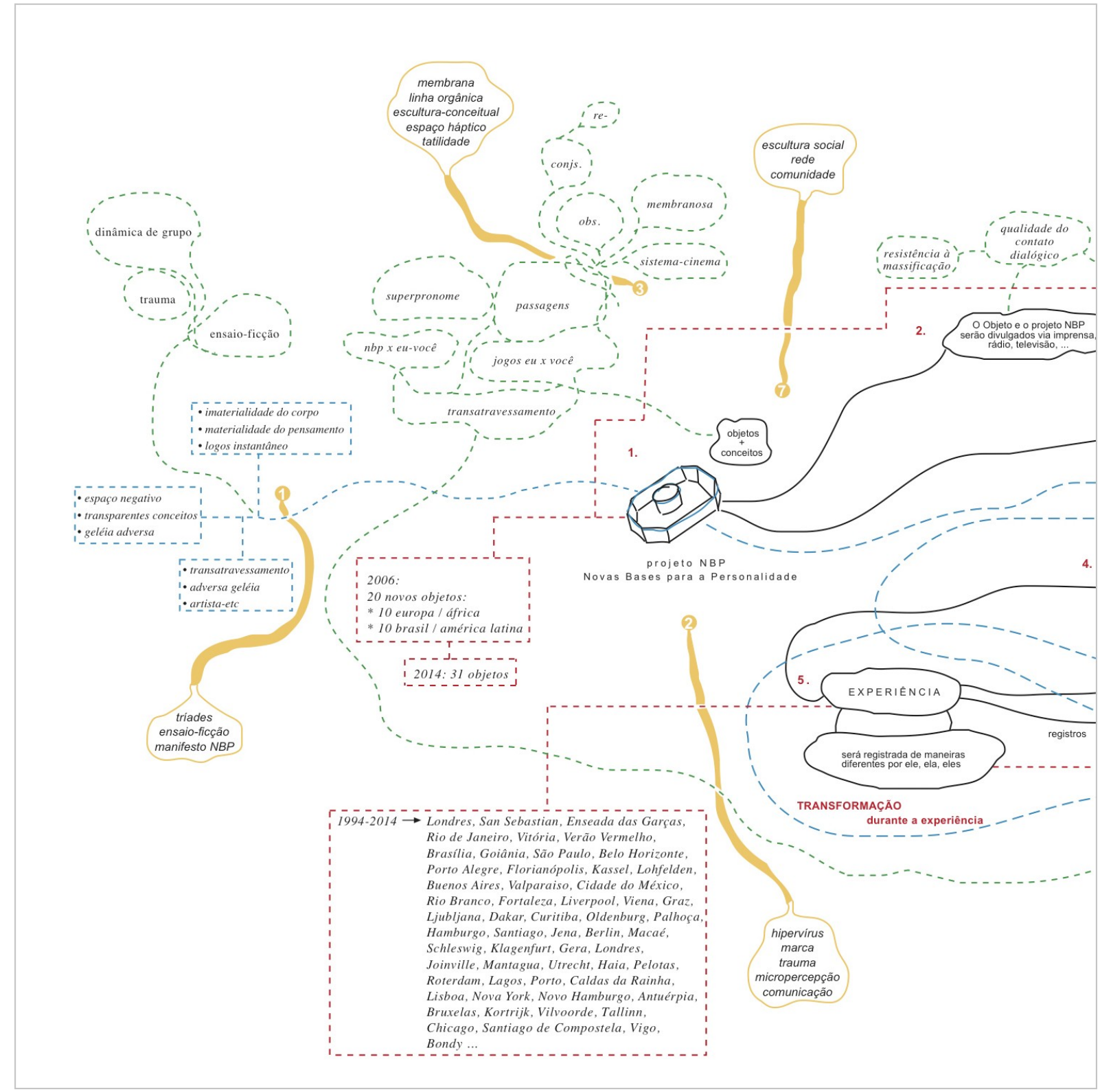

Fig. 1 - Ricardo Basbaum, Você gostaria de participar de uma experiência artística? - diagrama - fase 5 (detalhe), trabalho em progresso desde 1994, diagrama atualizado em 2014. Disponível em: http://www.nbp.pro.br/. Acesso em: 2 fev. 2017.

\section{Pesquisa artística dentro e fora da academia}

As discussões pioneiras em torno da pesquisa artística ou pesquisa em arte no Brasil vêm ocorrendo de forma crescente desde que um programa de pós-graduação em Arte foi criado na ECAUSP nos anos de 1970 (ZAMBONI, 2005; ZANINI, 2008; PRADO, 2009). A diversidade, complexidade

GODÓI, Vagner. A obra de pesquisa de Ricardo Basbaum.

PÓS:Revista do Programa de Pós-graduação em Artes da EBA/UFMG. v. 11, n. 22, mai-ago. 2021 Disponível em < https://doi.org/10.35699/2237-5864.2021.25627> 
e consistência da pesquisa em arte no Brasil, realizada em várias universidades públicas que contemplam esse tipo de pesquisa, reconhecida pelas agências de avaliação e de fomento, são resultado dos esforços de muitos artistas e pesquisadores da Arte, que criaram uma das primeiras experiências consistentes e duradouras de pesquisa do artista em universidades no mundo.

No texto "O artista como pesquisador", Ricardo Basbaum (2013a, p. 193) diz que "não há como escapar desta máxima: dentro da universidade, o trabalho de arte se transforma em pesquisa e o artista em pesquisador". Escreve-se "artista-pesquisador", diz ele, indicando para o aumento do número de artistas contemporâneos que atuam em várias universidades públicas pelo país,

desenvolvendo pesquisas, ministrando aulas, orientando alunos, organizando eventos e mesmo ocupando cargos administrativos. Isto pode indicar um momento particularmente favorável para a área de artes na universidade, uma vez que um número expressivo de artistas atuantes junto ao circuito de arte pode trazer, para dentro da academia, um fôlego de trabalho urdido em outras instâncias da interface arte/sociedade.

Ricardo Basbaum ingressou em 1985 no Curso de Especialização em História da Arte e Arquitetura no Brasil da Pontifícia Universidade Católica do Rio de Janeiro (PUC-Rio), criado e coordenado pelo artista Carlos Zilio. O artista diz que intuiu, pelo tipo de trabalho que desenvolvia, que seria muito difícil viver do mercado da arte, ainda mais nos anos de 1980, porque ele "não estava naquele enclave de artistas que buscaram uma relação direta com o mercado, atendendo a uma demanda". ${ }^{4}$ Dar aula de Artes era uma coisa que lhe interessava e poderia ser uma maneira de sobreviver como artista.

Hoje eu vejo que o meu trabalho também é sobre isso, sobre como a gente se inventa como artista num local qualquer, no meu caso em um local e um contexto específico que é o Brasil da abertura política dos anos 1980, início do neoliberalismo, enfim, o contexto de onde eu vim. ${ }^{5}$

No começo dos anos de 1990, o artista diz que tentou cursar um mestrado na área de Poéticas Visuais da USP e no Multimeios da Unicamp, mas acabou não sendo aceito em nenhum desses dois. Então, o artista resolveu ficar no Rio mesmo, que já era o lugar de sua residência, ingressando no mestrado da Escola de Comunicação da Universidade Federal do Rio de Janeiro (ECO-UFRJ), sob a orientação de Rogério Luz, um lugar onde havia um grupo de pesquisadores e professores voltados para o pensamento contemporâneo. Ali, Basbaum percebeu seu interesse não só pela aula, mas também pela escrita, como um lugar de expansão de sua prática como artista, em

GODÓI, Vagner. A obra de pesquisa de Ricardo Basbaum.

PÓS:Revista do Programa de Pós-graduação em Artes da EBA/UFMG. v. 11, n. 22, mai-ago. 2021 Disponível em < https://doi.org/10.35699/2237-5864.2021.25627> 
funções próximas do escritor, do pesquisador e do crítico. ${ }^{6}$ Basbaum fala que construiu sua carreira procurando a todo momento modos de atuação que não fossem necessariamente atrelados à compra e à venda de obras de arte, em um percurso de investigação e construção sobre o lugar em que ele, como artista, deveria ocupar. "É interessante que se perceba o artista para além do mero produtor de obras de arte" (BASBAUM, 2014a, p. 32-33), como alguém que também produz o lugar de produção da arte, como também o lugar do artista, ou seja, cria outros circuitos para a sua atuação, que podem ser independentes dos circuitos e das instituições tradicionais da arte. Dessa maneira, a universidade é hoje um lugar importante produzido pelo artista, para que ele possa trabalhar com liberdade reflexiva e de criação. Para Ricardo Basbaum, e para muitos outros artistas, a universidade é um lugar privilegiado, onde a arte pode ser pensada e produzida. A universidade pode ser entendida, mesmo com todos os seus protocolos e institucionalidades, como um lugar de descanso reflexivo e um lugar onde o artista e a arte podem sobreviver (financeira e, também, intelectualmente), não necessariamente atrelados ao mercado muito restrito, em direção a um pensamento coletivo e de troca de conhecimento. $E$ isso pode ser verificado na situação brasileira atual da pesquisa artística, que está bem desenvolvida e espalhada por vários programas de pós-graduação pelo país, representada por nomes significativos da arte contemporânea que se tornaram mestre e doutores.

Ricardo Basbaum (2014, p. 32) considera também um possível e outro "mercado de arte" fora do circuito em torno das galerias e feiras, bem como uma infinidade de atividades para as quais o artista acaba sendo pago, como organizar cursos e palestras, escrever e publicar livros e textos, percebendo o artista inserido dentro de uma produção cultural mais diversificada: "É parte do mercado de atuação do artista a realização de um seminário, uma palestra, a construção da escrita, junto à produção de uma obra que pode ser vendável; ações educativas, por exemplo".

Entre 1989 e 1994, Basbaum fez parte de um grupo no Rio de Janeiro, chamado Visorama, formado também por Carla Guagliardi, Analu Cunha, João Modé, Rosângela Rennó, Márcia Ramos, Valeska Soares, Brígida Baltar, Marcus André, Rodrigo Cardoso, Eduardo Coimbra, Márcia X, Alex Hamburger, entre outros. O grupo, que começou como grupo de estudos, se tornou algo muito próximo do que hoje é entendido como um coletivo de artistas, promovendo ciclos de palestras em várias cidades. Basbaum (2014a, p. 85) diz que, para seus participantes, o Visorama

GODÓI, Vagner. A obra de pesquisa de Ricardo Basbaum.

PÓS:Revista do Programa de Pós-graduação em Artes da EBA/UFMG. v. 11, n. 22, mai-ago. 2021 Disponível em < https://doi.org/10.35699/2237-5864.2021.25627> 
significou uma tomada de posição em relação ao circuito, investindo numa imagem do artista preocupado não apenas com os rumos de sua produção num ultrarrestrito mercado de arte, mas também com as conversas e comentários críticos que suas intervenções poderiam suscitar.

Pouco depois, ele será um dos editores da revista item, com os artistas Eduardo Coimbra e Raul Mourão, que teve seis edições entre 1995 e 2003. Segundo Basbaum, a revista, nesse sentido, foi para ele, "um passo além do Visorama, no sentido de poder fomentar o desenvolvimento de questões, proposições e ideias que trabalhassem em ressonância com nossa produção plástica" (BASBAUM, 2014a, p. 83). Essas duas ações transdisciplinares culminaram, entre 1999 e 2002, no estabelecimento da Agência Agora (Agência de Organismos Artísticos) e do Espaço Agora/ Capacete, que Ricardo Basbaum ajudou a manter como lugares de promoção da produção, exibição, pesquisa e discussão artística. A pesquisa do artista e suas qualidades teóricas e de pensamento coletivo nunca estiveram restritas ao ambiente universitário. Esses ambientes de pesquisa acabam sendo deslocados para grupos, espaços e revistas independentes, que se utilizam de outros circuitos ou os criam, e essas atividades de pesquisa e reflexão são parte importante da trajetória e do projeto poético de Ricardo Basbaum.

Assim, as ideias de Basbaum sobre o artista-pesquisador ampliam a ideia do que pode ser a pesquisa artística, uma vez que um fluxo entre academia e outros circuitos de legitimação da arte pode acontecer. $\mathrm{O}$ artista-pesquisador é aquele artista que está na academia, produz obras de pesquisa, e está aberto para a relação com outros circuitos. A academia é só mais um lugar para a sua atuação. A pesquisa artística na universidade abre-se para uma pesquisa consistente através dos circuitos artísticos já existentes, e também dos que são criados pelos próprios artistas, assim como o circuito aberto dentro da própria universidade como um desvio e como uma maneira de sobreviver na adversidade artística (não só brasileira) do reducionismo da arte orientada apenas ao mercado. Ricardo Basbaum representa, no contexto brasileiro, o artista preocupado com a reflexão e a criação de lugares para que essa reflexão seja feita: um grupo de pesquisas, uma revista, um coletivo, um espaço independente de pesquisas gerenciado por artistas.

GODÓI, Vagner. A obra de pesquisa de Ricardo Basbaum.

PÓS:Revista do Programa de Pós-graduação em Artes da EBA/UFMG. v. 11, n. 22, mai-ago. 2021 Disponível em < https://doi.org/10.35699/2237-5864.2021.25627> 


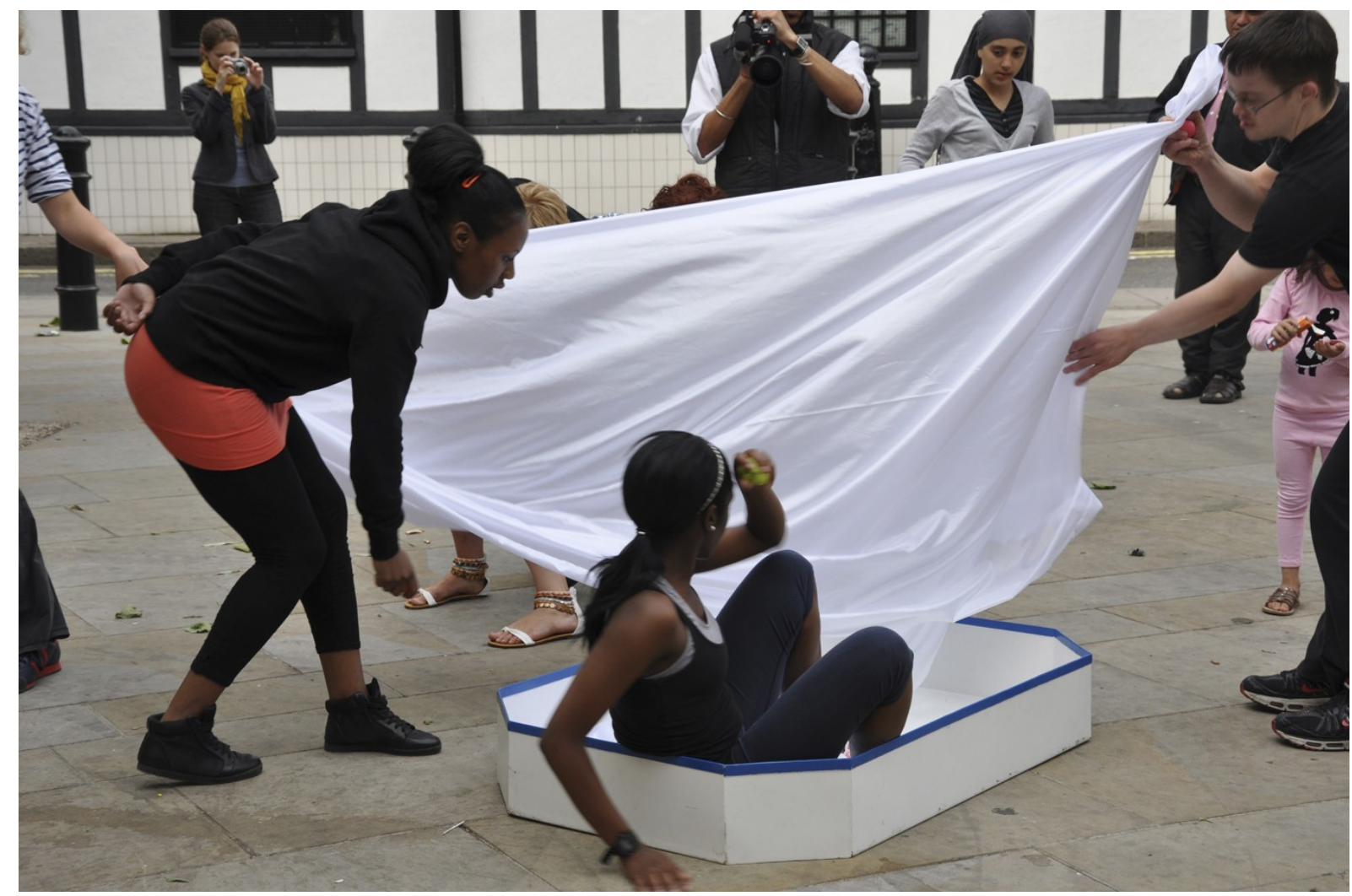

Fig. 2 - Ricardo Basbaum, Você gostaria de participar de uma experiência artística?, objeto de ferro pintado, experiência, 125 × 80 × 18cm, participação Dance Physics, Bruce Nockles, Ricardo Basbaum, [small operatic event], The Showroom Londres, UK, 2010. Foto: Cortesia do participante.

\section{Como funciona a obra de pesquisa}

A obra de pesquisa Você gostaria de participar de uma experiência artística? teve início em 1994, quando Ricardo Basbaum fazia um Master in Fine Art (MFA) na Goldsmiths, Universidade de Londres, no período do seu mestrado na ECO-UFRJ. Foi o ano em que Basbaum construiu o objeto e riscou o primeiro diagrama do projeto, em uma problematização, que tomava o artista à época, sobre as relações entre texto e obra de arte. ${ }^{7}$ A partir de então, essas preocupações artísticas tomam um caminho muito peculiar em direção à pesquisa e à teoria, e que vão culminar na exibição do projeto da documenta 12, de 2007, e na defesa, em 2008, do seu doutorado na área de Poéticas Visuais do Programa de Pós Graduação em Artes Visuais da ECA.

GODÓI, Vagner. A obra de pesquisa de Ricardo Basbaum.

PÓS:Revista do Programa de Pós-graduação em Artes da EBA/UFMG. v. 11, n. 22, mai-ago. 2021 Disponível em < https://doi.org/10.35699/2237-5864.2021.25627> 


\section{VOCÊ}

(indivíduo, grupo ou coletivo)

gostaria de participar de

uma experiência artística?

aceitaria levar para casa o objeto mostrado nesta fotografia?

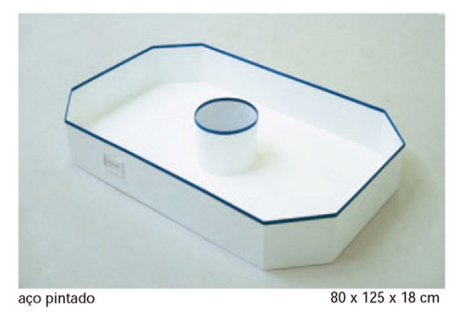

Isto é parte do projeto

NBP

Novas Bases para a Personalidade que envolve idéias de participação e transformação

uma investigação acerca do envolvimento do outro como participante em um conjunto de protocolos indicativos dos efeitos, condições e possibilidades da arte contemporânea

Fig. 3 - Ricardo Basbaum, Você gostaria de participar de uma experiência artística? - guia para participantes, trabalho em progresso desde 1994, guia atualizado em 2014. Disponível em: http://www.nbp.pro.br/. Acesso em: 2 fev. 2017.

Você gostaria...? está conectado a um projeto poético maior chamado projeto NBP - Novas Bases para a Personalidade, ocorrendo de forma paralela e imbricada. NBP fala sobre estruturas, projetos, programas, dispositivos e redes, fala sobre o novo que nasce da transformação como também sobre subjetividade e alteridade, o público e as conexões entre os corpos. A ideia, tanto da forma quanto da sigla, resulta em um sistema conceitual desenvolvido pelo artista que vai se complexificando conforme as obras vão surgindo e conforme todo o processo de pesquisa artística vai se desenrolando, entrelaçando "texto e imagem, aproximando as dimensões sensorial e conceitual" (BASBAUM, 2008, p. 117). NBP surgiu em 1989, com os primeiros objetos, firmou-se em 1990, com o texto “O que é NBP?", e acabou de se definir em 1991, com a criação da forma específica (BASBAUM,

GODÓI, Vagner. A obra de pesquisa de Ricardo Basbaum.

PÓS:Revista do Programa de Pós-graduação em Artes da EBA/UFMG. v. 11, n. 22, mai-ago. 2021 Disponível em < https://doi.org/10.35699/2237-5864.2021.25627> 
2007b, p. 73-76). A partir de então, vários dispositivos foram sendo criados em torno dessa forma: desenho de grades, disposição de móveis, formato de objetos, diagramas dispostos na parede, projetado nas cidades e nos mapas, aparecendo em vídeos, textos, jogos, oficinas e conversas.

Para entender o funcionamento da obra de pesquisa, que é composta de conexões e associações, linhas de pensamento e objetos, experiências e experimentos, ações e atividades, participações e colaborações, trabalhos e exercícios, processos de pesquisa acadêmica e artística, fluxos de energia e movimentos, é preciso fazer uma tentativa de exibir e descrever as muitas camadas complexas que formam esse tipo de obra. A obra de arte é esquematizada como um projeto (poético) de pesquisa, em que são lançadas as bases teóricas da pesquisa artística em desenvolvimento, processo que é esquematizado segundo um sistema conceitual organizado em tópicos e conjunto de ideias, compondo-se, muitas vezes, de problemas, hipóteses, objetivos, fundamentação teórica, em proximidade com a pesquisa acadêmica, aproveitando-se, de forma poética, de seus protocolos, visualidades e métodos. Essa estratégia fronteiriça é encontrada, às vezes sem distinção, na dissertação e na tese, nos artigos, escritos e teorias de artista, nas conversas e oficinas, nos dispositivos que o artista inventa para fazer circular pensamentos e sensações. Saber como a obra funciona, descrever seu funcionamento, nos mostra a complexidade dos jogos enredados criados pelos artistas, revela-nos as linhas poéticas ou as linhas de pesquisa, da pesquisa artística como obra de pesquisa, obra complexa e em rede, um diagrama-quadro propiciador de conexões e associações, pensamentos e sensações.

Em Você gostaria...?, um objeto é oferecido por Ricardo Basbaum à participação de pessoas ou grupos, artistas ou não, que são desafiados a realizar uma experiência artística a partir de um uso específico desse objeto específico. No "Guia para participantes", criado para apresentar e explicar como funciona o projeto, fica clara a liberdade que é dada ao participante, onde se lê que o objeto "pode ser usado de diferentes modos e você pode fazer qualquer coisa com ele: use-o como quiser, da maneira que achar melhor" (BASBAUM, 2014b).

GODÓI, Vagner. A obra de pesquisa de Ricardo Basbaum.

PÓS:Revista do Programa de Pós-graduação em Artes da EBA/UFMG. v. 11, n. 22, mai-ago. 2021 Disponível em < https://doi.org/10.35699/2237-5864.2021.25627> 


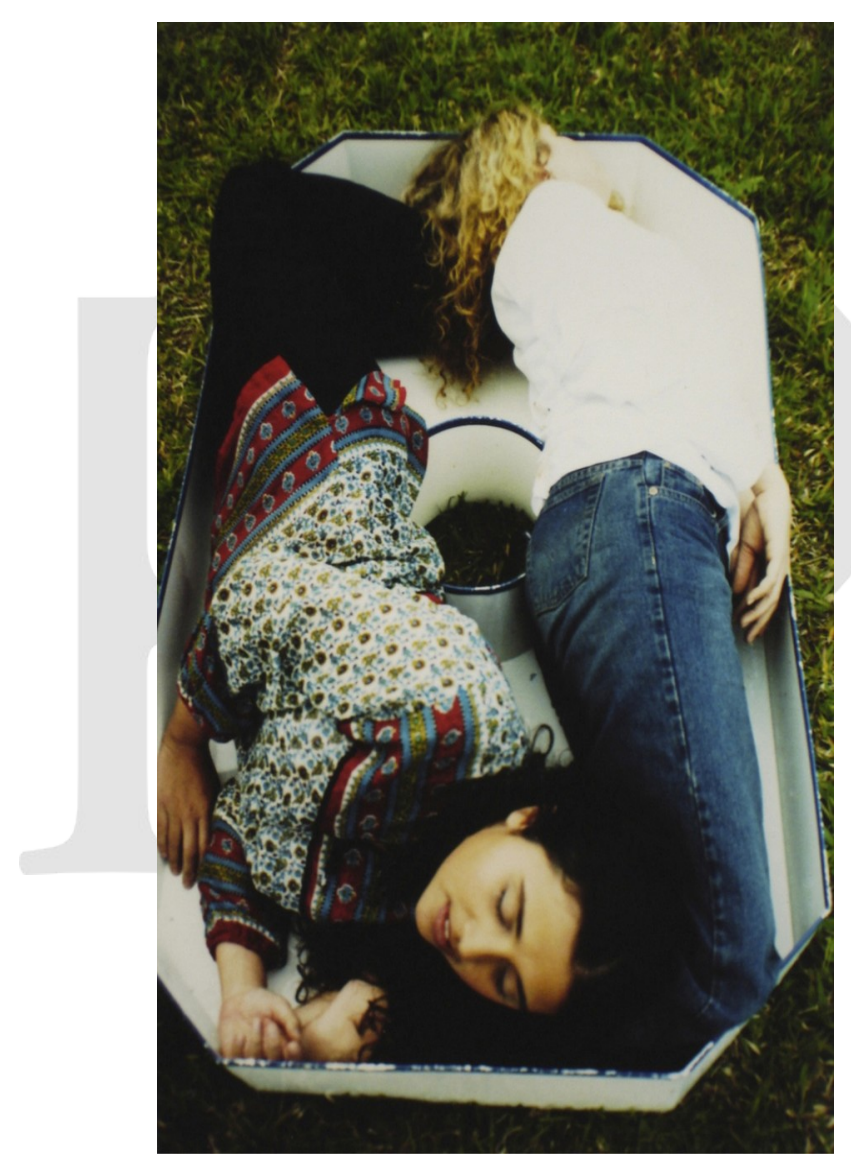

Fig. 4 - Ricardo Basbaum, Você gostaria de participar de uma experiência artística?, trabalho em progresso desde 1994, objeto de ferro pintado, experiência, 125 × 80 x 18cm, participação Grupo Laranjas, Porto Alegre, Brasil, 2002. Foto: Cortesia do participante.

O objeto tem uma "forma específica": é octogonal, tem um furo no meio e "oferece área interna a ser preenchida - tal qual um contêiner" (BASBAUM, 2008, p. 87) ou uma forma de bolo. Segundo Ricardo Basbaum (2013b), o projeto foi se formalizando "tentando perceber a circulação desse objeto, como objeto doméstico que pudesse ser levado para casa e depois retirado". É um objeto grande, medindo $1,25 \times 0,80 \times 0,18 \mathrm{~m}$, feito de aço esmaltado por processos industriais, todo branco mas com as bordas em azul-marinho.

A chapa, depois de assumir a sua forma por pressão, é mergulhada em esmalte líquido e queimada em forno. A borda é pintada à mão. Assemelha-se a um objeto de uso doméstico, um utensílio. $\mathrm{O}$ material, comumente chamado de ágata no Brasil, é utilizado em pratos, canecas, penicos e banheiras antigas. O design clássico branco e azul é atribuído a Falcon Enamelware, uma indústria britânica de utensílios de ágata que existe desde 1920. Basbaum (2013b) diz que esta foi a sua

GODÓI, Vagner. A obra de pesquisa de Ricardo Basbaum.

PÓS:Revista do Programa de Pós-graduação em Artes da EBA/UFMG. v. 11, n. 22, mai-ago. 2021 Disponível em < https://doi.org/10.35699/2237-5864.2021.25627> 
inspiração: “Eu já havia feito uma peça em fórmica, uma peça em napa e espuma, uma peça em ferro. [...] Eu estava passando um período em Londres, com uma bolsa de estudos, e acabei fazendo essa nova peça na linha de objetos domésticos que você encontra por lá".

A conexão entre Ricardo Basbaum com o interessado em participar pode se dar por inscrição, mas também por convite, com indicação de amigos ou instituições que estivessem abrigando o projeto, em determinado momento e em diferentes partes do mundo. Segundo Basbaum (2005a), no começo havia um esforço da parte dele para que esses contatos se dessem. "Agora me encontro na situação interessante de conhecer pessoas através do objeto, o que é muito prazeroso em termos de acesso a outras pessoas e circuitos". Na documenta 12, a distribuição foi orientada por um setor da organização da mostra. Em outros momentos há uma apresentação pública, dependendo do contexto em que o projeto está inserido, como uma palestra feita por Ricardo Basbaum para disparar os contatos de participação.

Depois disso, o objeto é enviado, dentro de uma logística muito variável. No começo, havia uma movimentação menor e o artista geralmente pagava pelo transporte. $\mathrm{O}$ artista fala que talvez o objeto "tenha ido do Rio pra Vitória de caminhão [...]. Aí ele volta para o Rio, depois foi pra Brasília. Quando ele foi pra Brasília eu lembro de ir no aeroporto botar em um avião". Então, o artista percebe que, a partir de determinado momento, as pessoas foram se organizando por si próprias para receber o objeto. De Brasília para Goiânia e de lá para Belo Horizonte; depois para Porto Alegre, Florianópolis e assim por diante, ou seja, o objeto começa a circular em uma rede, em um sistema. Depois, dentro do processo institucionalizado da documenta 12, houve dinheiro não só para o transporte dos objetos, via FedEx, como para a construção de mais novos objetos. A partir daí, todo o processo de envio acaba sendo, na maioria das vezes, custeado também pelas instituições que se interessam em recebê-lo, parte de uma exposição ou de um evento.

Há uma quantidade de objetos que circula: até hoje foram produzidos aproximadamente trinta objetos. Entre 1994 e 2005 um único objeto circulou. Segundo o artista, isso se deveu apenas a fatores econômicos, já que ele é múltiplo e de tiragem aberta, "não há diferença entre primeira, segunda e terceira, todas são rigorosamente iguais" (BASBAUM, 2013b). Com a documenta 12 foram fabricados dez objetos em Kassel e dez em Florianópolis, e foram distribuídos assim: seis em

GODÓI, Vagner. A obra de pesquisa de Ricardo Basbaum.

PÓS:Revista do Programa de Pós-graduação em Artes da EBA/UFMG. v. 11, n. 22, mai-ago. 2021 Disponível em < https://doi.org/10.35699/2237-5864.2021.25627> 
Kassel, um em Liverpool, um em Viena, um em Dakar, um em Liubliana na Eslovênia, um em Buenos Aires, um em Valparaíso no Chile, um na Cidade do México e sete circularam pelo Brasil. (BASBAUM, 2013c).

As pessoas e os grupos começam a participar, resultando em variados tipos de usos e atividades. $\mathrm{O}$ objeto fica um mês, aproximadamente, com o participante. A ideia é que seja passado adiante, que circule. Algumas experiências acontecem nas casas das pessoas, em ambiente íntimo e particular. Outras ocorrem entre amigos ou no espaço público. Alguns usos são cotidianos, como atribuir sentido no ambiente familiar como mesa, cama, armário, banheira, reservatório de água, bebedouro para animais, aquário, forma de bolo. Outras experiências assumem a linguagem e a pesquisa artística do artista que está participando, dando origem a outros objetos de arte ou usos performáticos. Algumas propostas expuseram o limite do sentido da circulação do objeto e até o desacordo do artista em relação a elas. O objeto já foi clonado e passado adiante, sendo o original destruído pelos participantes. Em outra experiência, o objeto foi doado a um museu, mas Ricardo Basbaum resgatou-o de volta à circulação (BASBAUM, 2005b).

O artista confere a responsabilidade sobre a experiência artística às pessoas que estiverem de posse do objeto, que devem cuidar para que uma escolha aconteça, uma atividade seja feita e que haja registro. Segundo Basbaum (2009, p. 60), o artista não desaparece, mas torna-se um "administrador dos processos propostos, atuando a favor da construção e organização de algumas leituras possíveis e de sua publicação".

Uma das responsabilidades do participante é registrar a utilização do objeto, é produzir e postar uma documentação. Documenta-se a obra no site www.nbp.pro.br, criado para a documenta de Kassel, e ajuda-se a automatizar esse processo de participação. Antes disso as negociações aconteciam com uma mediação maior do artista, em contato direto com as pessoas. No começo do projeto, que é anterior à popularização da internet, as respostas vinham sobretudo por correio, o que ajudava a elaboração de outros tipos de entregas, não só fotografias, mas incluía a elaboração e o envio de objetos artísticos feitos pelos participantes. É disponibilizada ao participante uma área logada no site com ferramentas para envio ou edição dos resultados de sua participação, como textos, imagens, sons, vídeos. O site, segundo artista, é um banco de dados onde se pode ver a história de participações (BASBAUM, 2007b).

GODÓI, Vagner. A obra de pesquisa de Ricardo Basbaum.

PÓS:Revista do Programa de Pós-graduação em Artes da EBA/UFMG. v. 11, n. 22, mai-ago. 2021 Disponível em < https://doi.org/10.35699/2237-5864.2021.25627> 
Há o momento da experiência do participante e o momento da exibição da obra em uma exposição de arte. Basbaum (2010) diz que o objeto não foi feito para ser uma peça de museu, e o modo como o projeto é pensado dispensa galerias e museus para poder funcionar. "Além disso, o site do projeto já é uma estrutura de exibição". Mesmo assim, o artista cria estratégias de exibição em bienais, museus, galerias ou centros culturais, com o uso de estruturas e dispositivos, além de colocar o objeto à participação. Na exposição individual conjs., re-bancos*: exercícios\&conversas, que aconteceu em Belo Horizonte em 2012, um computador foi disponibilizado para o acesso ao site do projeto.

O projeto começou a ser visto com mais regularidade, tanto no Brasil quanto no exterior, a partir da documenta 12, que teve a curadoria de Roger Buergel. Primeira tentativa de exibição dos resultados e da documentação gerada pelos participantes, a estrutura da obra, chamada por Ricardo Basbaum de estrutura arquitetônico-escultórica, estava presente no chamado Aue-Pavillon, um grande pavilhão temporário construído especificamente para a mostra daquele ano e localizado no gramado em frente à Orangerie, em Kassel. Ricardo Basbaum utilizou dispositivos, estruturas e módulos com que já vinha trabalhando, feitos de grades metálicas. A instalação foi composta de bancos, camas, colchonetes, almofadas, corredores, passagens e arquibancada. Monitores e computadores exibiam vídeos e fotografias em slideshow das experiências e o site do projeto como um grande arquivo. O diagrama era exibido em uma parede na parte externa da obra. Câmeras de vigilância filmavam o espaço da instalação, monitorando e gravando a vivência e participação do público da mostra dentro da estrutura, e essas imagens eram também exibidas em monitores. Segundo Ricardo Basbaum (2007c), a instalação funciona como uma membrana entre o projeto e a documenta 12, apresentando-se, deste modo, como "uma estrutura arquitetônico-escultórica que se abre para a experiência sensível e propõe um espaço para ser assimilado como vivência". O artista pensa, desse modo, em estratégias de exibição para a compreensão de seu trabalho no contexto de uma mostra de grandes dimensões, que se dá com a criação de um lugar complexo de exibição e convívio, recurso utilizado por ele em outros momentos, criando o que ele chama de "museu dentro do museu" ou "arquitetura dentro da arquitetura", um lugar autônomo dentro da própria mostra. Estratégia conceitual que, segundo o artista, busca proteger a autonomia da obra, negociando sua presença dentro do evento (BASBAUM, 2007c).

GODÓI, Vagner. A obra de pesquisa de Ricardo Basbaum.

PÓS:Revista do Programa de Pós-graduação em Artes da EBA/UFMG. v. 11, n. 22, mai-ago. 2021 Disponível em < https://doi.org/10.35699/2237-5864.2021.25627> 
Modos parecidos de exibição em escala menor foram vistos depois nas exposições coletivas Quase Líquido, realizada no Itaú Cultural em 2008; A Rua (De Straat), que teve a curadoria de Dieter Roelstraete, ocorrida no Museu de Arte Contemporânea de Antuérpia (MHKA) em 2011; e Aberto Fechado: Caixa e Livro na Arte Brasileira, que aconteceu na Pinacoteca do Estado de São Paulo em 2012, com curadoria de Guy Brett. Outros exemplos de exibição e funcionamento do objeto ocorreram, por exemplo, na 7a Bienal do Mercosul, em 2009, dentro do programa misto de curadoria educativa e residência artística, chamado "artistas em disponibilidade"; como participação e exibição de estrutura na mostra coletiva A Singular Form, na Secession de Viena, em 2014, com curadoria de Pablo Lafuente; como conversas na exposição El Contrato, parceria entre os espaços Bulegoa z/b e Azkuna Zentroa de Bilbao em 2014; além de fazer parte de outras obras como conversas-coletivas e re-projetando, dependendo do contexto de cada exposição.

\section{Pesquisa artística como um problema coletivo}

Depois de respondida a primeira pergunta - já que o "projeto é um ponto de interrogação, seu título é uma pergunta" (BASBAUM, 2013d) -, é hora de responder a outro problema, como uma "pergunta dentro de uma pergunta" (BASBAUM, 2000). O que fazer com o objeto, em qual lugar, que tipo de resposta será dada? A decisão é de quem estiver com o objeto. Para o artista, os participantes podem desenvolver experiências "a partir de temática ampla, tocando em questões em torno da arte e da vida, abordando o relacionamento entre o sujeito e o outro, conduzindo diretamente a processos de transformação" (BASBAUM, 2009). A obra de arte pode ser considerada um problema, pois o artista é "aquele que, em primeiro lugar, produz, fabrica (poiesis) e, em segundo lugar, produz/fabrica problemas, obstáculos" (BASBAUM, 2014a, p. 27-29). Nesse sentido, há uma aproximação da produção da obra de arte com a produção de experiências criadas pelo problema, ideia que também é próxima do pensamento e da problematização coletiva sobre o corpo e sobre o espaço público.

Essa é uma obra de pesquisa artística empreendida tanto por Ricardo Basbaum quanto pelos participantes como um "exercício coletivo de produção de pensamento sensível" (BASBAUM, 2009), um trabalho bastante conhecido não só por ter participado da documenta 12, mas pelo envolvimento de um número grande de artistas no Brasil: pessoas relacionadas a vários circuitos da arte, de programas de pós-graduação em Arte a coletivos e grupos em várias regiões do Brasil. Alguns

GODÓI, Vagner. A obra de pesquisa de Ricardo Basbaum.

PÓS:Revista do Programa de Pós-graduação em Artes da EBA/UFMG. v. 11, n. 22, mai-ago. 2021 Disponível em < $\underline{\text { https://doi.org/10.35699/2237-5864.2021.25627> }}$ 
artistas e grupos de artistas brasileiros que fizeram experiências, além de Jorge Menna Barreto, foram Brígida Baltar, coletivo SIM ou ZERO, Grupo de Pesquisa Corpos Informáticos, Divino Sobral, Carla Zaccagnini, Cristina Ribas, Cristiano Lenhardt, Elaine Tedesco, Yiftah Peled, Regina Melim, Teresa Riccardi, Jardim Miriam Arte Clube de Mônica Nador e a companhia teatral Ueinzz, entre outros. "Redes coletivas de produção de pensamento" (BASBAUM, 2007b, p. 77) são criadas para que as pesquisas artísticas de outros artistas entrem em colaboração com a pesquisa artística de Basbaum. Quando o artista convida alguém para participar de uma experiência artística, ele também está convidando a pesquisa daquela pessoa para adentrar a sua própria pesquisa. A partir disso, uma ideia de "produção coletiva do pensamento" é criada, pois todo participante "está efetivamente pensando o projeto, trazendo-o em direção a limites, testando possibilidades de seu funcionamento" (BASBAUM, 2008, p. 193).

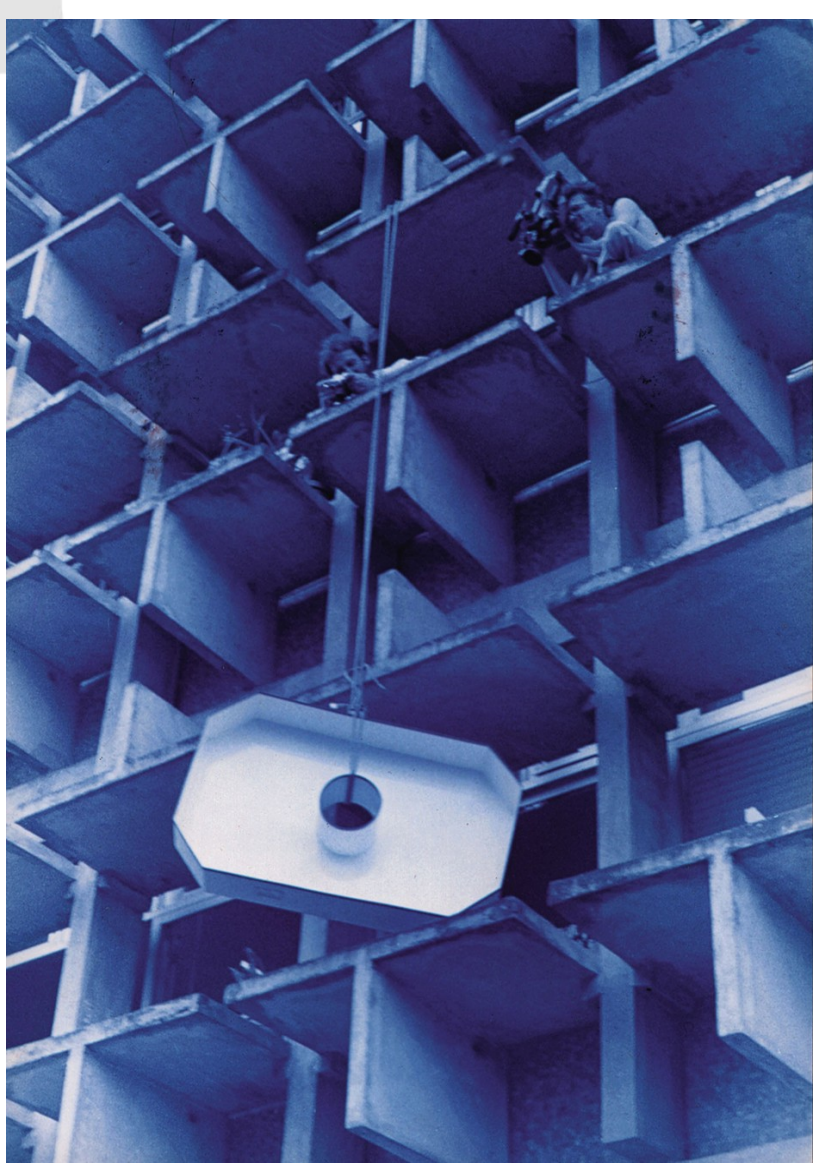

Fig. 5 - Ricardo Basbaum, Você gostaria de participar de uma experiência artística?, trabalho em progresso desde 1994, objeto de ferro pintado, experiência, 125 × 80 x 18cm, participação Grupo de Pesquisa Corpos Informáticos, Brasília, Brasil, 1997. Foto: Cortesia do participante.

GODÓI, Vagner. A obra de pesquisa de Ricardo Basbaum.

PÓS:Revista do Programa de Pós-graduação em Artes da EBA/UFMG. v. 11, n. 22, mai-ago. 2021 Disponível em < https://doi.org/10.35699/2237-5864.2021.25627> 
Basbaum (2016) diz que está em busca de respostas para os problemas que ele endereça ao outro. Respostas que ele espera que venham dos participantes que são convidados a experienciar o objeto - "não somente com o objeto, mas também com os conceitos que vêm junto com o objeto". Ao conjunto de todas as respostas geradas pelas participações com o objeto no projeto Você gostaria..?, retornadas para o artista em forma de arquivos, o artista dá o nome de romance crítico, expressão que ele utiliza para nomear esse "grande conjunto de falas, também polifônico, um conjunto de investidas críticas em relação" a seu trabalho. Basbaum (2007b) diz que a expressão, que foi incluída no diagrama de Você gostaria...?, surgiu em seu doutorado, porque ele foi percebendo que, nessa busca por "um jogo dialógico, de uma conversa coletiva", o projeto rumou para a constituição de um "pensamento coletivo".

Então, o artista percebeu que não conseguiria dar conta sozinho de todas as demandas e respostas dessas experiências, dadas a complexidade e a dimensão das conexões. No momento em que o participante "manuseia esse objeto, testa os limites do projeto, responde às questões que eu coloco ali, pensa o projeto à sua maneira, produz formulações ${ }^{\prime \prime}$, ele acaba pensando sobre a arte e o próprio projeto. Este termo serve também para que a responsabilidade de leitura das participações não recaia totalmente sobre o artista, que passa a se configurar como um gerenciador das respostas trazidas pelos participantes. A função principal do artista nesta obra é ler e administrar o "romance-crítico", o conjunto de respostas "que jamais conduz a soluções de curto prazo, mas à lapidação do problema como joia preciosa de lento processamento" (BASBAUM, 2008, p. 184).

\section{Considerações finais}

Pesquisadores, teóricos, críticos, curadores e artistas poderão explorar a obra de arte de Basbaum através de várias linhas poéticas, ${ }^{10}$ podendo ser da educação ou da mediação, da linha orgânica ou da escultura social, da performance ou da participação, do cotidiano ou do cinema, da arte postal ou do objeto técnico, do arquivo ou da história, da sociedade de controle ou da contaminação, da subjetividade ou do site-specificity, da comunicação ou da rede, entre outras, dadas a abertura e a complexidade de Você gostaria...?. Por outro lado, são colocadas em relevo as linhas poéticas relacionadas aos processos de pesquisa artística, dentro ou fora da academia. O objeto específico como um dispositivo para experimentações diversas é um instrumento de investigação por parte do

GODÓI, Vagner. A obra de pesquisa de Ricardo Basbaum.

PÓS:Revista do Programa de Pós-graduação em Artes da EBA/UFMG. v. 11, n. 22, mai-ago. 2021 Disponível em < https://doi.org/10.35699/2237-5864.2021.25627> 
artista gerenciador que dispara outras variadas pesquisas artísticas. No lugar do nome original da obra, partindo do contexto aqui colocado, pode-se perguntar também: Você gostaria de participar de uma pesquisa artística?

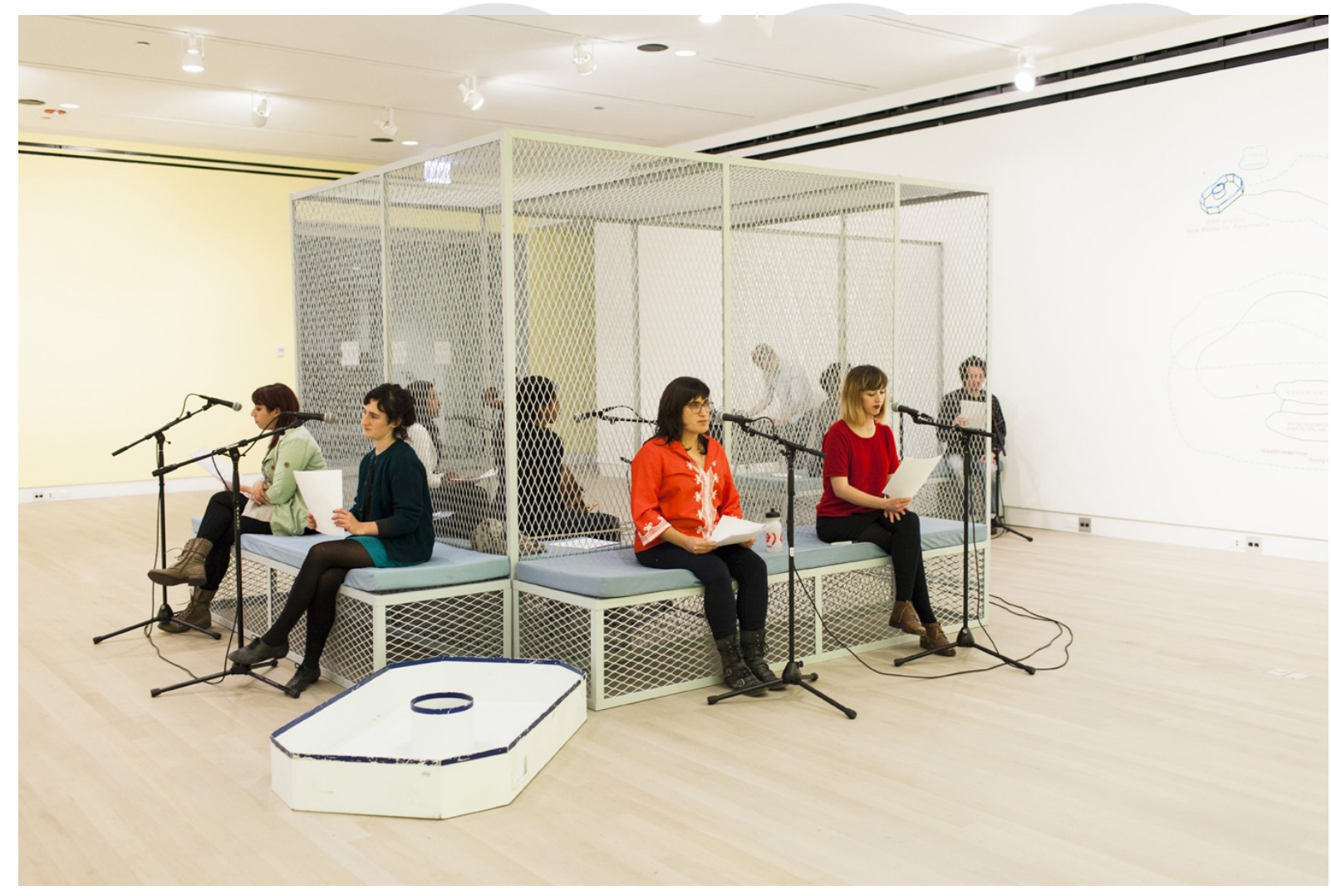

Fig. 6 - Ricardo Basbaum, conversa-coletiva (você gostaria...?), 2012. Leitura ao vivo e gravação com Tomeka Reid, Brian Holmes, Rachel Ellison, Sarah Mendelsohn, Nabiha Khan, Preema John, Ricardo Basbaum, Katherine Harvath, Monika Szewczyk. Apresentada no Logan Center Gallery, Chicago, Estados Unidos. Foto: Cortesia do artista.

A linha da pesquisa atravessa o projeto poético do artista Ricardo Basbaum porque: ele inclui um questionamento sobre a pesquisa artística e a imagem do artista que é pesquisador em seus textos; considera a produção artística vinculada ao universo discursivo e teórico, em que a criação dos conceitos está atrelada à obra de arte; utiliza conceitos e monta sistemas conceituais poéticos que parecem saídos de outro campo do conhecimento; pensa a arte e sua relação com a teoria, aquela que é feita por filósofos, pesquisadores e críticos, mas também aquela que é feita pelos artistas; traz o conhecimento e o pensamento para um ambiente de discussão pública e coletiva, desenvolvendo atividades participativas em torno de palestras, oficinas, aulas e conversas;

GODÓI, Vagner. A obra de pesquisa de Ricardo Basbaum.

PÓS:Revista do Programa de Pós-graduação em Artes da EBA/UFMG. v. 11, n. 22, mai-ago. 2021 Disponível em < https://doi.org/10.35699/2237-5864.2021.25627> 
aproxima-se da literatura e da poesia, não só da poesia visual, mas a partir das imagens que surgem da leitura; utiliza diagramas como dispositivos de exibição da pesquisa e desenvolve um pensamento diagramático; propõe obras de arte que podem ocorrer dentro de obras de arte de outros artistas, assim como outros artistas também acabam participando de suas obras; por fim, seu projeto poético extrapola o espaço expositivo ou o tempo da exposição, espalhando-se em vários eventos e conversas, distribuídos por vários dispositivos, objetos, ações e vivências.

Uma vez que a todo momento Ricardo Basbaum está no embate entre pesquisa artística produzida dentro e fora da academia, a problematização também adentra a poética da obra de arte em um questionamento sobre a diferença entre o lugar da arte e a própria obra de arte. Qual a diferença do escrito, teoria e livro de artista dentro ou fora da universidade? Assim como qual a diferença entre a aula ou a oficina que o artista ministra dentro da universidade daquela aula ou oficina que o artista diz ser parte integrante de sua obra de arte? Essas fronteiras não são respeitadas por Basbaum, que não está interessado em se comprometer com apenas um lugar ou circuito. $\mathrm{O}$ artista aproveita-se dessa multiplicidade de lugares em que a pesquisa artística pode acontecer, pressupondo que cada artista é um pesquisador, cada um com sua trajetória, projeto poético e questionamentos próprios.

Ricardo Basbaum conecta o campo textual, seja ele acadêmico, crítico ou teórico, com a obra de arte. $\mathrm{O}$ artista imagina um entrelaçamento entre a questão material da obra ou o modo como ela é exibida com todos os processos discursivos que a atravessam, todas as camadas de textos, conversas, relações e participações, que são parte da obra de arte e não precisam necessariamente aparecer no espaço expositivo. Mas esse pensamento assume uma materialidade na obra, que não é somente aquela que é exibida, mas que se encontra espalhada e distribuída como partes de um sistema conceitual que o artista engendra através de diagramas e teorias de artista. $\mathrm{O}$ artista vai além, pois o pensamento que atravessa tanto o texto quanto a obra tem uma materialidade, um pensamento tratado como se fosse material artístico, podendo sofrer operações e alterações como construção, ampliação, estilhaçamento, contração, acúmulo, ou seja, o pensamento é colocado em um plano diagramático que extravasa para o ambiente da arte ou, antes, para um ambiente de pesquisa artística.

GODÓI, Vagner. A obra de pesquisa de Ricardo Basbaum.

PÓS:Revista do Programa de Pós-graduação em Artes da EBA/UFMG. v. 11, n. 22, mai-ago. 2021 Disponível em < https://doi.org/10.35699/2237-5864.2021.25627> 
Toda pesquisa nasce de um problema, de uma pergunta que a anima, que lhe dá hipóteses e que guia para a criação, através de uma resolução. Você gostaria de participar de uma experiência artística? nasce dessa dúvida, que recai sobre a própria arte e também sobre o modo como a obra se relaciona com as pessoas e vice-versa. Nesse caso, vemos também a pergunta como um convite para que a outra pessoa faça uma investigação, uma experiência livre sobre o campo da arte. Vemos aí nessas perguntas uma sugestão de pesquisa, um convite à pesquisa artística, que pode ser feita por artistas ou não, dentro de uma ideia muito mais ampla de arte, e que é próxima da vida e de outros campos do conhecimento. Você gostaria...? favorece e apresenta uma imagem da pesquisa, porque, no limite, compõe-se de elementos intelectuais e em proximidade com outros campos do conhecimento: a teoria de artista, o pensamento esquematizado e organizado em diagramas, a colocação de perguntas e problemas como um elo comum entre pesquisa científica e pesquisa artística, a criação de um pensamento coletivo. Um ambiente teórico é instalado com diagramas e textos na obra de arte, que agora se coloca em uma condição simultânea de produção artística e produção do entendimento de seu funcionamento.

GODÓI, Vagner. A obra de pesquisa de Ricardo Basbaum.

PÓS:Revista do Programa de Pós-graduação em Artes da EBA/UFMG. v. 11, n. 22, mai-ago. 2021 Disponível em < $\underline{\text { https://doi.org/10.35699/2237-5864.2021.25627 }>~}$ 


\section{REFERÊNCIAS}

BASBAUM, Ricardo. O que é NBP? Rio de Janeiro: Espaço Cultural Sérgio Porto, 1993. Folder. Disponível em: <https://bit.ly/2EKpike>. Acesso em: 13 out. 2017.

BASBAUM, Ricardo. (?)? Pergunta dentro de pergunta. Arte \& Ensaios, Rio de Janeiro, n. 7, 2000.

BASBAUM, Ricardo. Diferenças entre nós e eles. In: Entre lugares: arte e pensamento. Colóquio do Programa de Pós-Graduação em Ciência da Literatura da UFRJ, 2005a. Disponível em:

$<$ https://bit.ly/3kV4LsA >. Acesso em: 12 out. 2017.

BASBAUM, Ricardo. Relatório de uma visita ao MASC no dia 13 de junho de 2005. 2005b.

Disponível em: <http://www.nbp.pro.br/doc/relatorio_masc_1178.pdf>. Acesso em: 6 fev. 2017.

BASBAUM, Ricardo. Além da pureza visual. Porto Alegre: Zouk, 2007a.

BASBAUM, Ricardo. Fluindo de diferença para diferença. Entrevista concedida a Cecília Cotrim.

Cultura e Pensamento, n. 2, p. 70-77, 2007b.

BASBAUM, Ricardo. Entrevista a Ricardo Basbaum. Entrevista concedida a Daniel Reyes León. Arte

y Crítica. Relatos Críticos de Arte, 2007c. Disponível em: <https://bit.ly/3l0iDl8>. Acesso em: 17 fev. 2017.

BASBAUM, Ricardo. Você gostaria de participar de uma experiência artística (+NBP). 2008. 158 f. Tese (Doutorado em Poéticas Visuais) - Escola de Comunicações e Artes, Universidade de São Paulo, São Paulo, 2008.

BASBAUM, Ricardo. Você gostaria de participar de uma experiência artística. In: DE CARO, Marina (Org.). Micropolis experimentais: traduções da arte para a educação (Projeto Pedagógico da 7a Bienal do Mercosul). Porto Alegre: Fundação Bienal do Mercosul, 2009, p. 60-75.

BASBAUM, Ricardo. Entrevista con Ricardo Basbaum. Entrevista concedida a Paola di Modesta. Interartive: A Platform for Contemporary Art and Thought, 2010. Disponível em:

<https://bit.ly/2GoRSry>. Acesso em: 23 fev. 2017.

BASBAUM, Ricardo. O artista como pesquisador. In: . Manual do artista-etc. Rio de Janeiro: Beco do Azougue, 2013a. p. 193-201.

BASBAUM, Ricardo. Carbono entrevista Ricardo Basbaum. Entrevista concedida a Marina Fraga.

Revista Carbono, n. 2, Rio de Janeiro, 2013b. Disponível em: <https://bit.ly/3je3jRr>. Acesso em: 23 out. 2016.

BASBAUM, Ricardo. Só funciona nessa responsabilização do outro por uma ação não idealizada. Arte \& Ensaio, Rio de Janeiro, v. 25, p. 7-33, 2013c.

BASBAUM, Ricardo. Ricardo Basbaum. Entrevista concedida a Renato Rezende e Ana Kiefer. In: KIFFER, Ana; REZENDE, Renato; BIDENT, Christophe (Org.). Experiência e arte contemporânea. Rio de Janeiro: Circuito, 2013d. p. 68-84.

GODÓI, Vagner. A obra de pesquisa de Ricardo Basbaum.

PÓS:Revista do Programa de Pós-graduação em Artes da EBA/UFMG. v. 11, n. 22, mai-ago. 2021 Disponível em < $\underline{\text { https://doi.org/10.35699/2237-5864.2021.25627 }>~}$ 
BASBAUM, Ricardo. Mediações. In: FERNANDES, Mariana Queiroz (Org.). Longitudes: a formação do artista contemporâneo no Brasil. São Paulo: Casa do Povo; Anamauê, 2014a. p. 24-33.

BASBAUM, Ricardo. Guia para participantes do projeto "Você gostaria de participar de uma experiência artística?". 2014b. Disponível em: <https://bit.ly/2EJ0au9>. Acesso em: 2 fev. 2017.

BASBAUM, Ricardo. Sobre o et cetera. Entrevista concedida a Duda Kuhnert. Revista Beira, 9 out. 2016. Disponível em: <https://bit.ly/3i54lbS>. Acesso em: 15 out. 2016.

BASBAUM, Ricardo et al. Complexidade, metabiologia e criatividade. Revista Carbono, Rio de Janeiro, n. 7, 2014. Disponível em: <https://bit.ly/2S8NkZ2>. Acesso em: 3 fev. 2017.

COSTA, Luiz Cláudio da. O efeito-arquivo: a transversalidade como espaço discursivo. In: ENCONTRO NACIONAL DA ANPAP: Transversalidades nas Artes Visuais, 18., 2009. Anais... Salvador: ANPAP, EDUFBA, 2009. p. 2157-2171.

COTRIM, Cecilia. Arte e deriva: a escrita como processo-invenção. Arte \& Ensaio, Rio de Janeiro, ano 15, n.17, p. 64-73, 2008.

HOLMES, Brian. A personalidade potencial. Trans-Subjetividade na Sociedade de Controle.

Cadernos de Subjetividade, Núcleo de Estudos e Pesquisas da Subjetividade, PUC-SP, São Paulo, ano 8, n.13, 2011.

LAFUENTE, Pablo. Ricardo Basbaum, Or That Elusive Object of Emancipation. Afterall, n. 28, p. 7889, Autumn/Winter 2011.

LINGNER, Michael. Reflections on/as Artists'Theories, 2006. Disponível em:

<https://bit.ly/2EMC0iq >. Acesso em: 26 jun. 2016.

MACIEL, Katia. Ricardo Basbaum: a geometria do conceito e a participação comunicacional. In: Luiz Cláudio da Costa (Org.). Dispositivos de registro na arte contemporânea. Rio de Janeiro:

Contracapa, 2009.

PRADO, Gilbertto. Breve relato da Pós-Graduação em Artes Visuais da ECA-USP. ARS, São Paulo, v. 7, n. 13, p. 98-101, 2009. Disponível em: <https://bit.ly/33aYnHu>. Acesso em: 13 jan. 2018.

ZANINI, Walter. Elementos sobre a pesquisa em Artes Plásticas no Brasil e ANPAP (1987-1989). In: RAMALHO E OLIVEIRA, Sandra; MAKOWIECKY, Sandra (Org.). Uma história da Associação Nacional de Pesquisadores em Artes Plásticas. Florianópolis: UDESC, 2008. p. 33-38.

ZAMBONI, Silvio. Situação atual da pesquisa em/sobre arte. In: MOREIRA, Maria Carla Guarinello de Araújo (Org.). Arte em pesquisa. Londrina: EDUEL, 2005. p. 189-204.

GODÓI, Vagner. A obra de pesquisa de Ricardo Basbaum.

PÓS:Revista do Programa de Pós-graduação em Artes da EBA/UFMG. v. 11, n. 22, mai-ago. 2021 Disponível em < https://doi.org/10.35699/2237-5864.2021.25627> 


\section{NOTAS}

1 Essa primeira parte é composta pelos capítulos “Migração das palavras para imagem" (artigo publicado na revista Gávea, em 1995), “Pensa com arte: o lado de fora da crítica”, “Diagramas e processos de transformação" e "Ricas articulações".

2 Entrevista concedida por Ricardo Basbaum para esta pesquisa.

3 Entrevista concedida por Ricardo Basbaum para esta pesquisa.

4 Entrevista concedida por Ricardo Basbaum para esta pesquisa.

5 Entrevista concedida por Ricardo Basbaum para esta pesquisa.

6 Entrevista concedida por Ricardo Basbaum para esta pesquisa.

7 Entrevista concedida por Ricardo Basbaum para esta pesquisa.

8 Entrevista concedida por Ricardo Basbaum para esta pesquisa.

9 Entrevista concedida por Ricardo Basbaum para esta pesquisa.

10 Ver outros tipos de discussões originais sobre Você gostaria...? em: Cotrim (2008), Costa (2009); Maciel (2009), Holmes (2011) e Lafuente (2011). 